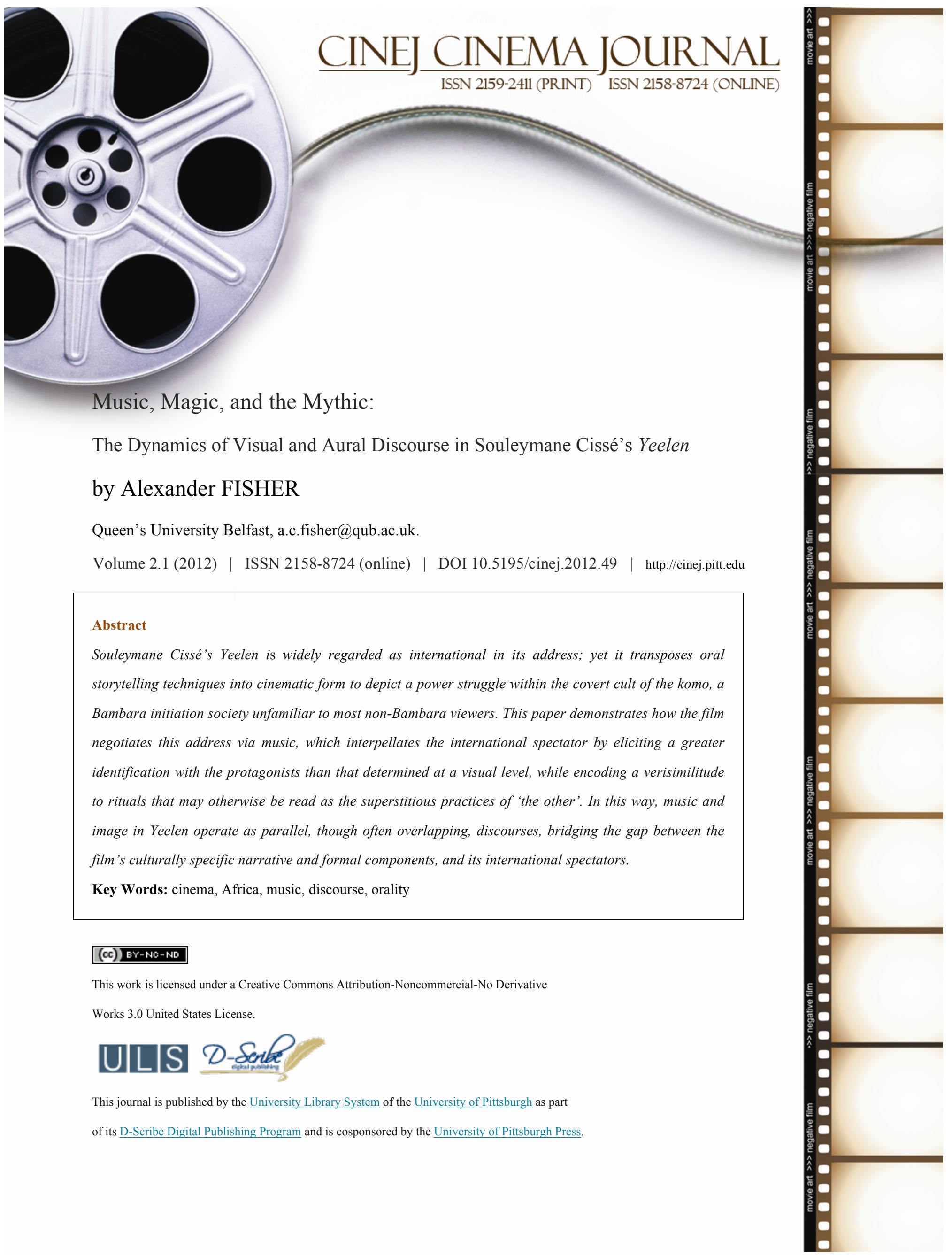




\section{Music, Magic, and the Mythic: The Dynamics of Visual and Aural Discourse in Souleymane Cissé's Yeelen}

A single, lingering frame defines the visual style of Yeelen (Souleymane Cissé, Mali, 1987); as our protagonist, Nianankoro (Issiaka Kane), embarks on a journey of initiation in order to confront his tyrannical father, Soma (Niamanto Sanogo) - a member of an oppressive, covert Bambara cult known as the komo - he discovers a mound of termite clay, a substance that in Mande folklore is imbued with 'magic properties' (MacRae, 1999, p. 133). ${ }^{1}$ For Nianankoro, these properties represent a renewed hope of defeating the murderous intent of Soma, who is threatened by his son's coming of age and consequent acquisition of the powers of the kore, which he will use in a bid to end the komo's reign of social oppression. ${ }^{2}$ It is the framing of Nianankoro - as he gazes into the distance bearing an expression of single-minded determination - that most readily defines Yeelen's visual style; while another director might have zoomed or tracked to a close-up of our protagonist, shifting our focus from the progression of the narrative events to an identification with the psychology of that character, Cissé holds the frame at a medium close-up, denying us a glimpse into Nianankoro's mind. In eschewing the psychologically-based visual organisation of classical cinema - thus denying spectator identification with our protagonist - Yeelen calls attention to the film's enunciation, a call that emulates the self-conscious performance of the griot, the storyteller of African oral tradition. In this sense, the film transposes into cinematic terms the techniques of oral narrative. However, such a reading of the film is complicated when one pays attention to Yeelen's sound track; once this dimension of enunciation is brought into play, the language of the film becomes far harder to define.

For critics such as Manthia Diawara, Yeelen belongs to a wave of African films, produced in the 1980s, that sought to represent, in an international context, a sophisticated pre-colonial Africa, countering the distorted representations of the continent circulating in the West (particularly those of the ethnographic film), and thus undermining the dominant, Western representations of the continent as primitive. Categorising the films as part of a 'return to source' tendency, Diawara argues that these movies possessed the shared objective of proving 'the existence of a dynamic African history and culture before the European colonization' (1992, p. 160). For Diawara, filmmakers working within this genre (including Idrissa Ouedraogo and Gaston Kaboré, as well as Cissé) achieved this in part by appropriating the techniques of oral performance, inscribing the griot's self-conscious strategies of

CINEJ Cinema Journal: Alexander FISHER

Volume 2.1 (2012) | ISSN 2158-8724 (online) ｜ DOI 10.5195/cinej.2012.149 | http://cinej.pitt.edu 
enunciation via a film style that called the cinematic narrator into the foreground, thus defining a specifically ‘African' film 'language'.

Thus, Diawara was one of the first critics to identify the use of the oral performer's techniques in African cinema, demonstrating how 'return to the source' films refigure cinematic conventions to inscribe an oral mode of narration within their enunciative components. In his account of the visual inscription of oral narrative techniques in Idrissa Ouedraogo's Tilai/The Law (Burkina Faso, 1990), Diawara demonstrates how 'return to the source' films refigure the norms of Western cinema. Here the use of the static camera is understood as the inscription of the narrator's presence:

At the end of the film, the poetic way in which Kougri picks up the rifle and shoots Saga brings together film history and the African oral traditions. Because the camera is static and the acting looks clumsy, the shot reminds us of early cinema. But the distance between the characters and the spectator, the refusal to let the spectator into the characters' minds, is also a trait of the oral traditions. We know that we are being told a story by a third person (the griot or the filmmaker), and every shot must be negotiated through that narrator (1992, p. 164).

Thus, in Tilai, the static camera becomes the enunciative strategy through which the griot is inscribed, the selfconscious disavowal of the viewer's identification with the protagonists signalling the presence of the narrator. In this way, Tilai attempts to depict a pre-colonial African culture via a self-conscious enunciation that resembles the strategies of the oral performer, thus forging a film language rooted in African cultural forms.

However, the 'return to the source' films' attempts to realise a pre-colonial Africa, untouched by the ravages of colonialism, were not always well-received; according to Diawara, some critics argued that the films, far from undermining the Western (mis)conceptions of Africa, in fact reinforced images of the continent as 'other' and 'exotic', and were 'influenced by the vision of the European anthropologists' (ibid, 1992, p. 160). ${ }^{3}$ This is particularly problematic in Yeelen, since it deploys a narrative that is concerned with the highly covert komo, a cult with which very few non-Bambara viewers will be familiar, and which in many ways fulfils the stereotypes of 
Africa as 'other' (stereotypes that are sustained in the ethnographic film). Since a function of the 'return to the source' category was 'to prove the existence of a dynamic African history and culture before the European colonization' (Diawara, 1992, p. 160), one of Cissé's objectives may have been be to put such techniques on the world cinematic stage, thus calling into question the dominance of Western modes of narration. Therefore, an international address was essential to the 'return to the source' films' political project, initiating a tension between that project and the films' potential to invoke the 'ethnographic gaze', a gaze that regards the events depicted on screen as 'other'. In Yeelen, this problem is compounded by the relative interpretive inaccessibility, for the nonBambara spectator, of the film's narrative events, which, when related through the prism of Cissé's unique visual style, run the risk of invoking the distantiated ethnographic gaze in which the events on screen are exoticised. As David Murphy has pointed out, 'Africans other than Bambaras might be a bit nonplussed at certain points in the film. In fact, even Bambaras cannot be expected to understand all of the film's many-layered symbols, for the simple reason that only a select few are supposed to know all seven levels of the komo' (2000, p. 246).

In many ways, music is the means through which Yeelen negotiates these problems, accounting for the nonBambara spectator's unfamiliarity with the film's narrative events, as well as its particular enunciation of these events. In this sense, Yeelen deploys parallel discourses that operate between the modalities of its filmic enunciation, negotiating an address to both local and global spectators, the latter of which Cissé has described as 'the uninitiated' (Diawara, 1988, p. 15) (in a gesture towards the initiation ritual of the komo). Visually, Yeelen deploys a cinematic re-working of the enunciative components of oral performance, calling attention to the 'performance' of its narrative in a manner that eschews the 'invisible montage' of classical cinema, while musically the film refigures a number of strategies typical of classical cinema, perhaps even effacing the presence of the (griot-like) cinematic narrator that is emphasised visually. Thus music operates as a discursive bridge between the non-Bambara viewer and the film's obscure subject matter, while it restores spectator identification with the film's protagonist. Moreover, music concurrently encodes elements of verisimilitude, suspense, and mystery to rituals that the 'uninitiated' viewer, familiar with the norms of Western ethnography, may otherwise misinterpret as the practices of an inferior 'other'.

Thus, as Nianankoro encounters the termite mound clay, and we witness his resolve to defeat his tyrannical father, the distancing effect of the camera, held at a medium close-up (see fig. 1) and only subtly following his 
movements, is counteracted with the gradual fade-in of a repetitive, steady motive to the beat of four (in musical terminology known as a 'time signature' of ' $4 / 4$ '). The gradual fade-in of the $4 / 4$ motive here becomes a substitute for the zoom/track to close-up (the absence of which in turn calls attention to the cinematic narrator). Grasping two handfuls of the clay, Nianankoro gazes ahead towards the camera with an expression of determination as the music continues to fade-up. Determined to absorb and mobilise the clay's magical properties, the image of his fixed gaze combines with the increasing volume of the steady music, consolidating the link between our protagonist's psychological determination and the inevitability of his confrontation with Soma (see fig. 1).

\section{fig. 1}
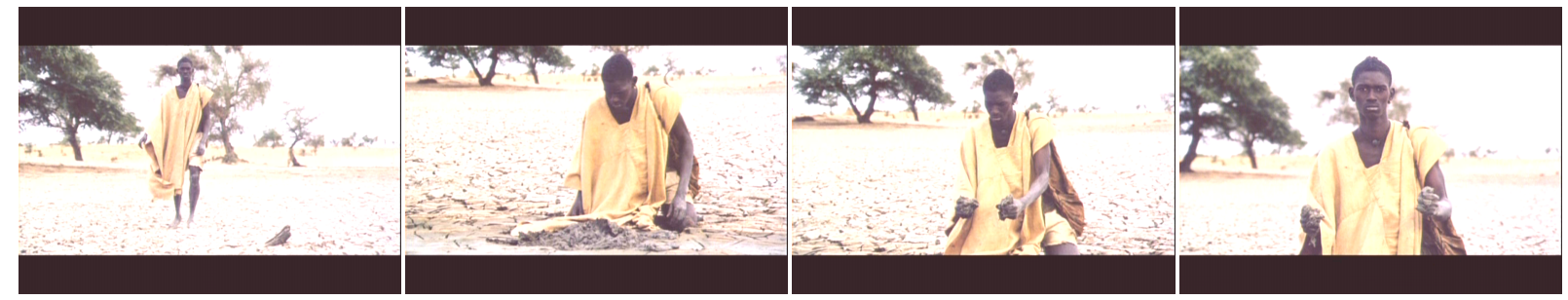

The music's gradual increase in volume thus operates as a surrogate for a gradual zoom-in from three-quarters shot to close-up. Whereas classical cinema might deploy the close-up technique here, emphasising the character's agency in determining the direction of the narrative, Cissé chooses instead to hold the camera at the three-quarter shot, transposing into cinematic form the conventions of oral narrative in which the presence of the narrator stands between the listener and his/her identification with the protagonist. The absence of the camera's shift of emphasis from the narrative to the psychological, typically achieved via the zoom to close-up, is therefore complicated by the sound mix. The fade-up, when heard against the medium close-up of Nianankoro, shifts our attention from the question of narrative transience to the question of character motivation and agency.

The modus operandi of cinema's alignment of spectator engagement with a character's psychology have been articulated in great detail by the exponents of 'Screen Theory', the fundamental components of which enable a more detailed articulation of Yeelen's restoration of spectator identification, which in turn denies 'the ethnographic gaze'. In particular, Laura Mulvey’s renowned work on cinema's construction of the spectator provides a valuable means of understanding the function of the music. The crucial components of this were laid out in the seminal work 'Visual Pleasure and Narrative Cinema' (1975) in which Mulvey identified two dimensions of the cinematic 
spectator's gaze, based around Freud's notion of scopophilia and Lacan's identification of the 'mirror phase' of human development. The first gaze involves the fulfilment of the scopophilic or voyeuristic drive to observe the 'object of desire'. Mulvey argues that since patriarchy positions male and female roles as active and passive respectably, cinema in patriarchal society objectifies the female figure, positioning the gaze of the spectator as the gaze of the male. The second gaze involves a narcissistic identification with the characters in the diegesis, in whom the viewer sees a reflection of him or her self. This is achieved by way of a return to the mirror phase (where the child for the first time is able to recognise his or her own reflection), in that the spectator is able to identify with the human forms depicted in the pro-filmic event. By invoking this identification, classical cinema is able to erase the distinction between the look of the camera and the spectator, and in turn the viewing subject's awareness of his/her act of looking. Thus the scopophilic drive may be reduced to the urge to see the human form objectified, or to identify with one's own reflection. Crucially, in the context of this discussion, Mulvey argues that this positioning occurs in cinema through the orchestration of a set of 'looks':

There are three different looks associated with the cinema: that of the camera as it records the profilmic event, that of the audience as it watches the final product, and that of the characters at each other within the screen illusion. The conventions of narrative film deny the first two and subordinate them to the third, the conscious aim being always to eliminate intrusive camera presence and prevent a distancing awareness in the audience. Without these two absences (the material existence of the recording process, the critical reading of the spectator), fictional drama cannot achieve reality, obviousness, and truth (1975, p. 17).

Mulvey breaks ground as to the ways in which film positions its spectators to identify with the 'reality' depicted on screen. For Mulvey, classical cinema renders the first two looks invisible, while avant-garde film, which frequently distances spectator engagement, simply allows the two looks to remain visible. Classical cinema achieves its verisimilitude by effacing the first two looks - the spectator's gaze at the camera and the camera's filming of the pro-filmic event - leaving us with the diegetic characters' looks at each other. 
Thus, classical cinema aims to 'eliminate intrusive camera presence and prevent a distancing awareness in the audience', the precise opposite of the visual strategies deployed in Yeelen, in which the intrusion of the camera is apparent through the absence of the close-up, through which the 'material existence of the recording process' remains visible. The classical paradigm of cinema has, by convention, created an illusion of invisible cinematography, with eye-line matches, the shot-reverse-shot, and the emphasis of the close-up, providing narrative cues that encourage within the spectator a narcissistic identification with the protagonist in which s/he fantasises about being the subject in a primordial return to Lacan's mirror stage of development, effacing the presence of the first two looks. The disavowal of these strategies in Yeelen reminds the spectator of the act of looking-at-the-camera-looking-at-the-pro-filmic-event. In turn, this alerts the viewer to the presence of the filmmaker-narrator who turns the camera at these events - thus the narrator's presence looms large in the narrative presentation since, as with Tilai, "we know that we are being told a story by a third person (the griot or the filmmaker), and every shot must be negotiated through that narrator' (Diawara, 1992, p. 164), a fundamental aspect of Yeelen's reconfiguration in cinematic terms of the enunciative strategies deployed in oral performance.

However, these techniques are also reminiscent of the visual strategies deployed by the ethnographic film in that they structure Mulvey's first two looks as visible. Indeed, the ethnographic film is arguably 'about' looking; the films posit the act of looking as the empirical basis upon which knowledge may be obtained through scientific observation, recording, and archiving. In this sense, ethnographic cinema acts as a kind of filmic museum; the viewer is made aware that s/he is looking at a camera's visual recording of the 'other'. The films of Jean Rouch perhaps exemplify these strategies, being orchestrated by an ideology founded on the perceived objectivity of the eye, an ideology that Martin Jay has conceptualised as 'ocularcentrism' (Jay, 1988, pp. 312-324, and 1993, pp. 186-187). Using Jay's terminology, Anna Grimshaw has argued that 'Rouch...is deeply committed to an "ocularcentric" project. Vision is elevated as the noblest of the senses, and it is privileged as a source of knowledge about the world' (2001, p. 90). Ethnographic cinema in this sense is primarily concerned with the act of looking and the objectification of the images on screen, imbuing them with the illusion of scientific integrity. However, the desire to 'look' in ethnographic film is fulfilled by the objectification and consequent fetishisation of the pro-filmic events as museum artefacts.

CINEJ Cinema Journal: Music, Magic, and the Mythic: The Dynamics of Visual and Aural Discourse in Cissé's Yeelen

Volume 2.1 (2012) ｜ ISSN 2158-8724 (online) ｜ DOI 10.5195/cinej.2012.49 | http://cinej.pitt.edu 
Yeelen's strategies of distantiation - resembling the disavowal of classical cinema's subordination of the first two looks identified by Mulvey (which actually provides the means upon which the forms of classical cinema are refigured as a means by which to signal the presence of the narrator) - are strikingly similar to, and could be misinterpreted as, the strategies deployed in the ethnographic cinema of Rouch, operating as an invitation to 'observe' the pro-filmic events in Yeelen from the uncritical gaze of the 'ethnographic eye'. However, the distance achieved in Yeelen differs from the distance achieved in the ethnographic film. In Yeelen the narrator looms large as a mediating figure in the film - the link between the spectator and the $13^{\text {th }}$ century-set narrative for which we only have the narrator's word as to its accuracy. In oral cultures, the griot also privileges the act of performing the narrative over the events of the narrative itself. This is reflected in the ways in which Yeelen refuses to allow the spectator any kind of narcissistic identification with the protagonist. As Paul Willemen summarises this, '[i]n conventional narrative cinema, attempts are made to make the viewer/film look coincide with the camera/profilmic event look, and a considerable panoply of strategies is deployed to erase the marks of the presence of the camera's look as distinct from the viewer's' (1994, p. 106). Yeelen removes spectator identification by refusing to mask this distinction, and as such emphasis is shifted to the question of how the narrative is told, rather than what is told. In this sense, Yeelen could be understood as mobilising a distantiation technique that provokes the spectator to consider his or her own position as witness to a particular re-articulation of oral narrative techniques. In literate, industrial discursive regimes, the act of calling attention to the presence of the cinematic narrator almost invariably unmasks the marks of the subject in the 'reader-viewer' and invokes a self-awareness of his/her own act of looking, an act of looking that invokes the distantiated engagement of the ethnographic gaze.

Thus, music in Yeelen positions the international (non-Bambara) viewer - to a degree - by restoring the viewer's 'cloak of invisibility' via the subordination of the first two looks identified by Mulvey. The film's music may indeed be read as a strategy to efface the first two looks in a manner similar to classical cinema, a strategy necessitated by the clandestine nature of the events depicted within the pro-filmic event. The film demonstrates a self-conscious awareness of its visual discourse's potential to exoticise Bambara culture for the non-Bambara viewer (a concern expressed in dominant critiques of 'return to the source' films). Thus music is a function of Yeelen's positioning of the non-Bambara viewer, the 'uninitiated' viewer unfamiliar with seeing 'magic' as 'reality', and the 'supernatural' as 'the natural', represented within a naturalist framework which is complicated even further by its particular reconfiguration within the terms of oral narration. 
Hence music's ability to act as a surrogate for the close-up is deployed at several points in the film. This is almost always achieved via the $4 / 4$ motive initially heard when Nianankoro discovers the termite clay. However, the music's meaning in relation to Nianankoro is, at one point, made concrete in a rare use of the close-up; in one scene, in which Nianankoro is taken captive (after he is caught apparently trying to steal cattle as he enters the land of the Peul), the $4 / 4$ motive returns, as the Peul warriors lead him to their king. In long-shot we see the group making their way towards the camera (see fig. 2) as the music fades in. The group stop to drink, and the camera lingers on a mid-shot of Nianankoro as the increasing volume of the $4 / 4$ motive suggests a build toward narrative climax. The direct connection made between Nianankoro's gaze and the music's fade-up inserts a link between the protagonist's psychological state and the music's sense of climax achieved through the cumulative effect of the persistent 4/4 motive. Nianankoro holds a gaze of unwavering determination, his intention to complete his initiation rituals and confront his corrupt father never being in question. Thus, the $4 / 4$ motive becomes aligned with Nianankoro's determination to complete his journey and overcome the powers of his father. This, in turn, provides a means of representing the character's fundamental role in the narrative progression to the final showdown between father and son. In this way the confrontation of the two powers is related to the protagonist's psychological state, the music allowing the spectator into the mind of Nianankoro in a manner characteristic of classical cinema.

\section{fig. 2}
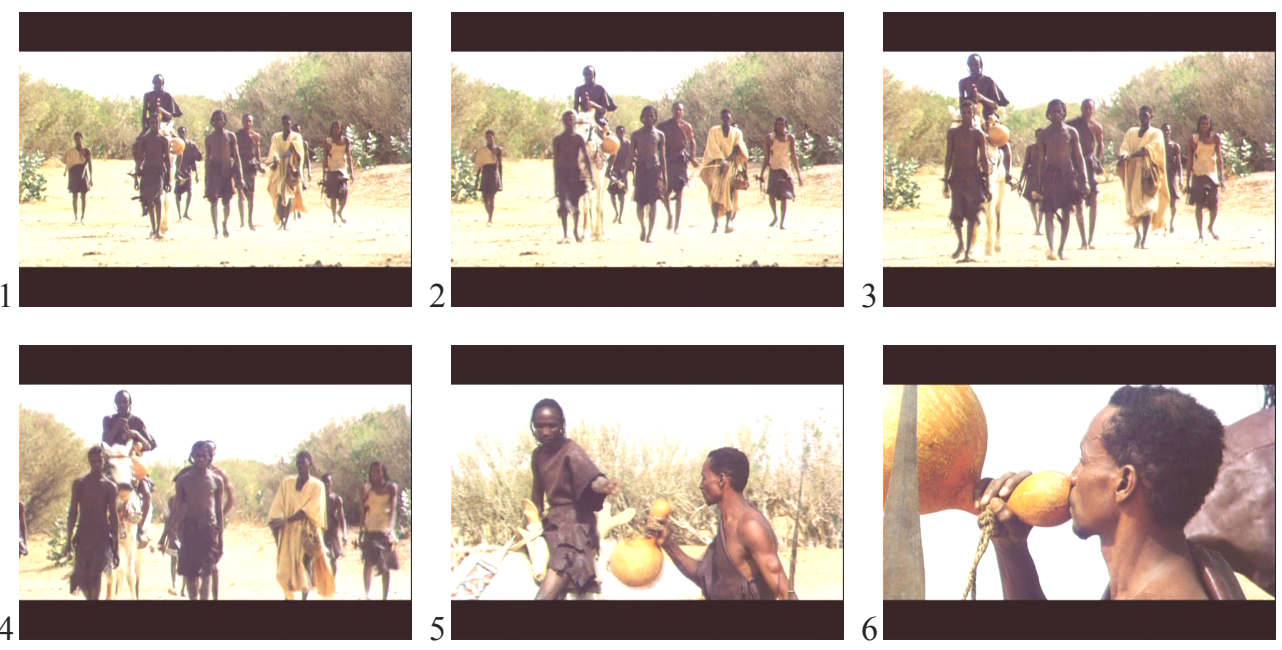

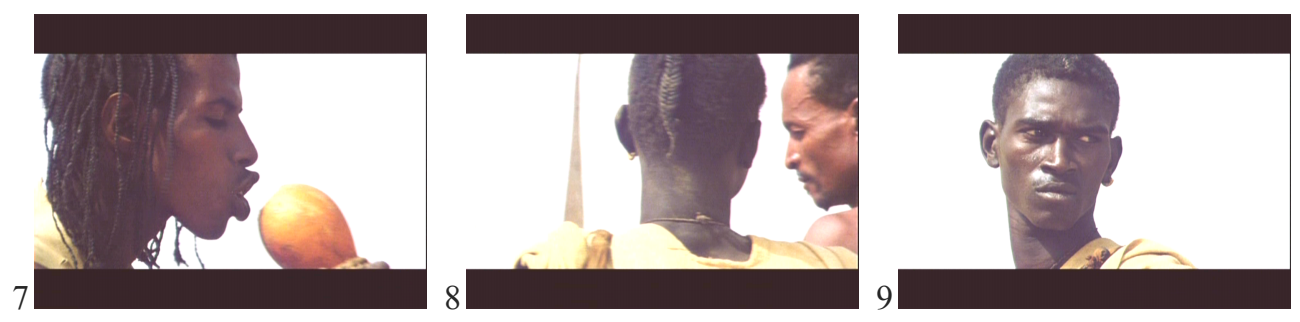

Therefore, Yeelen's use of music is fundamental to its rejection of 'colonial' discourses surrounding 'otherness' (see Said, 1988), particularly in terms of the way in which it is used to convey a sense of verisimilitude in relation to the obscure komo rituals we see on screen, imbuing them with 'believability'. In this sense, music not only replaces the psychological emphasis provided by the conventions of classical cinematography, but also imbues the diegetic events with a verisimilitude achieved by music's ability to evoke the 'mythic'. In Overtones and Undertones: Reading Film Music Royal S. Brown argues that music provides film with a mythic structure which he defines, via Jurij Lotman' distinction between the 'mythic text' and the 'plot text', the former of which employs a cyclical notion of temporality lacking a clear 'beginning' and 'end' (Brown, 1994, p. 9). It is this cyclical temporality that, for Brown, allows Claude Lévi-Strauss to see music as presenting 'mythic structure in an almost pure state' (Brown, 1994, p. 10). Many of these mechanisms are apparent in Yeelen, in which music may be understood as expressing notions of cyclical-temporal motion. Thus the 'mythic' sound of the music used is a result of the musical associations that occur via the cultural coding process that imbues certain musical idioms with certain meanings. In this way, the diegetic space of the film is musically transported beyond its ontological boundaries to suggest its position within 'the mythic', effacing its diegetic perimeter that calls its enunciative strategies into visibility. Music in this sense continues to undermine those aspects of narration - such as the presence of the narrator - that are called into being once the viewer becomes conscious of the marks of the subject. Furthermore, music allows the representation of social and belief systems that Western ideology has predominantly structured as 'other' to achieve verisimilitude through their association with Western conceptions of the mythic. Likewise, the anachronistic use of electronically generated and amplified instruments within the soundtrack removes the music from the temporal location of the diegesis, functioning beyond the geo-political and effacing its temporal and spatial location. Music operates, via its cultural coding, in a realm beyond the diegetic, beyond the earthly and beyond the culturally specific, imbuing the film with a cultural and temporal universalism that is contrary to the geo-politically specific events depicted diegetically. 
From this perspective, it is unsurprising that Yeelen's music almost always bears a 'mythic' relationship with the potent powers of sorcery that are unleashed in the diegesis. As such, the film's music acquires its intensity of presence through its relative absence. From the moment of its first occurrence, music is almost exclusively tied to the power of kore, primarily functioning as the calling card of the mysterious powers held by the cult that Nianankoro is destined to destroy. In this way, it becomes something like a 'leitmotiv', although not through the repeated use of a single musical figure (motive) but instead through the connections made between particular musical idioms and the kore; the music becomes a reifying surrogate for the kore's abstract and ineffable 'power'. This is evident during the first section of the film, which consists in part of caption cards explaining the kore's significance as the seventh stage of the Bambara komo cult. We learn that 'Le komo est pour les bambaras l'incarnation du savoir divin. Son enseignement est basé sur la connaissance des "signes" des temps et des mondes. Il embrasse tous les domaines de la vie et du savoir' ['For the Bambara, the komo is the incarnation of divine knowledge. Its teaching is based on the understanding of time and the world's "signs". It incorporates all areas of life and knowledge']. The captions go on to explain the powers that lie in kolonkolanni, the magic pylon that 'finds what is lost and punishes wrongdoers'. Since the captions explain the significance of the cult in Bambara culture, they represent the film's most explicit address to a non-Bambara audience. The early scenes suggest that the film oscillates between a concern with depicting the specificities of Bambara rituals at the same time as evoking a sense of their power, thus removing the viewer from an 'ethnographic gaze', in which the practices represented may be interpreted as primitive spectacle. Thus, from the outset music is deployed as a strategy to articulate the significance of the kore powers, an emphasis that draws the spectator away from the possibility of an ethnographic gaze that could be invoked by a more naturalistic representation of Bambara society.

This is evident in the music heard over the opening captions; here a high-pitched bell is joined by a lower pitched bell (even quieter than the first), the bells' atonal and arhythmic qualities locating them within the realm of the ambient rather than the musical. In the film's first shot, a long static take shows us the sun rising in time-lapse over a deserted rural setting. This peaceful and tranquil equilibrium is shattered as the film cuts to the image of a chicken being sacrificed by fire; over its terrified crowing an amplified, plucked bass string instrument pounds out a five note staccato motive, immediately calling the spectator's attention to the significance of the power being mobilised by Soma. The fifth (and final) note of the motive is sustained over a disconcerting discord (for the 
music theory-minded this chord oscillates around the D major triad), which continues to haunt the soundtrack long after the chicken's sacrifice.

The percussive, accentuated motive emphasises the initiation of Soma's search for Nianankoro and simultaneously the release of the power of the kore that takes place through the sacrifice of the chicken and the activation of the powerful kolonkolanni, the 'divining rod' that will allow Soma to locate his son. The music emphasises the narrative moment - the release of the potent kore powers - that will be the catalyst for the rest of the film's events. Once the flutes join in on the final note, the sustaining of the discord suggests that the kore's powers, so abruptly initiated, are now released and pervading the diegetic spaces and beyond, the sustained chord suggesting their permanence and omnipresence. The flute chord aurally resembles a product of nature (the wind), produced outside of the control of humans. The music's wind-like sound (it is played on wind instruments) compares the powers of nature to the powers of the kore. This contrasts directly with the percussive sound of the bass stringed instrument, which is a far more defined, clear tone that is audibly produced via the actions of a human being. Likewise, the sustained flute chord contrasts with the percussive five note motive which appears to initiate its execution. The flute chord embodies the supernatural aspect of the narrative, while the bass motive embodies the profane actions that necessarily prefigure the release of those powers, exemplified by the violent and aggressive ritual undertaken by Soma. In this sense the music sonically articulates the link between the material actions of the members of the komo fellowship, and the potent and pervasive powers that they abuse. Thus, from the outset, the film instigates a musically articulated duality between individuals and the 'supernatural', and the rituals that link the two aspects of komo society.

In this way, the kore powers become specifically associated with tonality. Before the chicken's sacrifice, only the bell's atonal ring is heard on the soundtrack (at a very low volume). Its position as diegetic, ambient sound is unclear; indeed its presence on the soundtrack may well go unnoticed by the viewer. Once the kore's powers are mobilised, tonality becomes an emphatic aspect of the soundtrack that is directly associated with these powers. The violent immolation of the chicken is then contextualised as Cissé flashbacks the narrative and we see Soma sitting before kolonkolanni as he cries out his vindictive ritual chant of vengeance in which he accuses Nianankoro of stealing the komo secrets, a distorted account of his son's threatening coming of age that is used as a justification for his destruction (later of course, we learn that Nianankoro is in fact a threat because he intends to 
use his powers to confront his corrupt father). Once again the chicken's sacrifice is seen, and it becomes evident that Soma is able to use his powers to achieve this, the chicken and a pyre suddenly appearing to combust without any physical intervention. No music accompanies this section however; while music articulated the controlled rage of the kore power's release, the film then moves on to a more naturalist representation of the komo ritual, the concern being for the detail of the specific practices employed by these rituals, rather than for the evocation of a sense of their power. Having already interpellated the viewer unfamiliar with the significance of the rituals subsequently shown on screen, the film then employs a less emphatic use of music, although the haunting discord of the flutes remains in the background, recurring at several key points in the film.

In the final scenes, Nianankoro and Soma engage in their fatal confrontation in which the release of their full powers results in both their deaths. Subsequently the voice of the kore is heard, vindicating the abuses committed by the former komo regime, while we see Nianankoro's young son inheriting the kore power in the form of an egg, a symbol of that power's rebirth through Nianankoro (MacRae, 1999, p. 137). Notably, only silence accompanies these images, a fact that may be attributed to the komo power's new material tangibility as an egg shaped incarnation. Nianankoro's son, yet to come of age, is unable to utilise its powers, and therefore they will lie dormant in their new material form until he completes his initiation. The use of silence here suggests the restoring of the equilibrium set out in the film's opening moments, in which the kore powers are dormant and no music is heard. This reinforces the music's explication of the presence/absence of the kore powers, solidifying its position as the sound of the kore, the abstract, ineffable presence that has had such a profound effect on the material world of the diegesis.

Encoded as both the embodiment of the kore powers, and as an articulation of character psychology, Yeelen's music brings the spectator 'closer' to the events in the diegesis, effacing the presence of the cinematic narrator that is emphasised visually, and which operates as an index of the film's appropriation of oral enunciative strategies. The particular characteristics of the various aesthetic modalities in the film therefore suggest an acknowledgement of the diversity of the film's viewing subject positions, from those 'initiated' in the ways of the komo, to the casual film festival spectator.

CINEJ Cinema Journal: Music, Magic, and the Mythic: The Dynamics of Visual and Aural Discourse in Cissé's Yeelen

Volume 2.1 (2012) ｜ ISSN 2158-8724 (online) ｜ DOI 10.5195/cinej.2012.49 | http://cinej.pitt.edu 
Evidence of the film's address to these diverse subject positions exists in Cissé's own words on the film, which provide further clues as to the particular functions of the text's various aesthetic modalities:

For the first time the film decodes the secret ritual described by the song that...[Malians usually hear]... on the radio... My film positions the spectator in the midst of these secrets and keeps him/her busy looking, interpreting, exploring. It is this level of the film that is incredibly exciting for the Malian spectator. For the spectator who is not initiated, I mean the American, French or British, I am sure that the film is perceived literally. I mean that this spectator hears the ritualistic song, reads its translation; but, this direct translation is not what is expressed by the film. The sentences are codified and refer to other objects which obey the rules of a specific knowledge. The rules of this knowledge can only be decoded by initiates of the 'Komo' (Diawara, 1988, p. 15).

Cissé's words demonstrate a concern for the 'positioning' of the spectator; indeed, his words regarding the 'literal' interpretation of the film potentially drive Yeelen's use of music, which interpellates the 'uninitiated' spectator who may otherwise misinterpret what $\mathrm{s} /$ he sees in ethnographic terms. Thus, as the music emphasises the connections between the film's events and Nianankoro's powers, the spectator is reminded of the significance of what $\mathrm{s}$ /he is witnessing, with the music guiding them through a narrative that may otherwise be perceived 'literally' as the rituals of an exotic 'other'. Yeelen therefore negotiates tensions of address generated between local and global discursive regimes; the film encourages an engaged international spectatorship through music, alerting the viewer to those aspects of the narrative that are important, and compensating for the lack of visual emphasis (typically articulated in classical cinema through techniques such as the close-up), which is generally discarded in the director's search for a new African 'film language'. Thus, the film accounts for the tensions between its international audience, the obscurity of the events depicted, and its particular inscription of oral performance, with a use of music that recalls the norms of classical cinema in its effacement of the first two looks orchestrated by that cinema (looks which remain visible at the level of Yeelen's visual track), thus allowing the film - at certain levels - to achieve 'reality, obviousness, and truth' (Mulvey, 1975, p. 17). 
At the same time, the music's incorporation within the structure of the Yeelen, which is both economical while consisting of a unique instrumentation, allows the film to avoid any clichéd similarity to conventional classical film scoring, while subtly appropriating aspects of its form to explicate its narrative and align spectator identification with the protagonist. The significance of these musical strategies only fully becomes clear when one considers the integrity with which the film eschews classical cinema's conventions at a visual level, in an attempt to inscribe the enunciative characteristics of oral performance. In this way, Yeelen places both its obscure subject matter (depicting the type of practices that have historically been dismissed as primitive), as well as the possibility of a specifically African 'film language' (recalling oral enunciative strategies), on the international stage, negotiating both oral and literate, industrial discursive regimes, in an address to both the 'initiated' and 'uninitiated' spectator.

\section{Endnotes:}

${ }^{1}$ An excellent account of Yeelen's narrative and its relationship to Bambara initiation rituals is available in MacRae (1999, pp. 127-140).

${ }^{2}$ S. M. Eno Belinga (1985) describes the different levels of Bambara initiation rituals. These are the komo, the nama, the kono, the n'domo, the tywara, and the kore. The kore, as is explained during the opening of Yeelen, is the highest level.

${ }^{3}$ Diawara goes on to cite Thérèse-Marie Deffontaines's review of FESPACO '89, in which she describes Idrissa Ouedraogo's Yaaba as a 'simple village story. A postcard which is magnificently photographed. Every shot is an aesthetic success. Yaaba provides the spectator with an idyllic image of an Africa which is devoid of every material contingency' (in Diawara, 1992, p. 160).

\section{REFERENCES:}

Brown, R. S. (1994). Overtones and undertones: reading film music. Berkeley, Los Angeles and London: University of California Press.

Diawara, M. (1988), 'Souleymane cisse’s light on Africa', Black Film Review, 4(4), 13-15.

Diawara, M. (1989). 'Oral literature the african film; narratology in wend kuuni ' in Pines and Willemen (Eds.) pp. 199-211.

Diawara, M. (1992). African cinema: politics and culture. Bloomington and Indianapolis: Indiana University Press. Eno Belinga, S. M. (1985). La literature orale africaine. Issy les Moulineaux: Les classiques africains. 
Grimshaw, A. 2001. The ethnographer's eye: ways of seeing in modern anthropology. Cambridge: Cambridge University Press.

Harrow, K. (Ed.) (1999). African cinema: postcolonial and feminist readings. Trenton, NJ: Africa World Press Inc. Jay, M. (1988). The rise of hermeneutics and the crisis of ocularcentrism. Poetics Today, 9 (2), 312-324.

Jay, M. (1993). Downcast eyes: the denigration of vision in twentieth century french thought, Berkeley CA: University of California Press.

MacRae, S. H. (1999). Yeelen: a political fable of the komo blacksmiths/sorcerers. in Harrow (Ed.), pp. 127-140.

Mulvey, L. (1975). Visual pleasure and narrative cinema. Screen, 16 (3): 6-18.

Murphy, D. (2000). Africans filming africa: questioning theories of an authentic african cinema. Journal of African Cultural Studies, 13(2), 239-249.

Pines, J. and Willemen, P. (Eds.) (1989). Questions of third cinema. London: BFI.

Said, E. (1985). Orientalism, London and New York: Penguin Books.

Willemen, P. (1994). Looks and frictions, London: British Film Institute. 